DOI: 10.20472/IAC.2018.044.052

JULIE WEN

Western Sydney > University , Australia

\title{
THE IMPACT OF VOLUNTEER TOURISTS: CASE STUDY OF MEIXIAN TEAM
}

\begin{abstract}
:
Volunteer tourism has been growing as an important segment of youth tourism. This paper takes Meixian Team ( Meixian Dui) as the case study. College students in Guangzhou, Southeast China, ride bicycles to rural China to help with primary teaching in rural Guangdong Province. By means of in-depth interviews, the research attempts to analyse their reflection and personal experience in relation to their volunteer tours. Young volunteers developed their personalities during their journey of helping rural children with limited resource. There were diverse modes of personal and interpersonal interactions among the research respondents. These volunteer tourists manifested how their experience resulted in shifts in personal attitude and world views of Chinese colleague students.
\end{abstract}

\section{Keywords:}

Change, China, Rural, Travel, Volunteer 